\title{
Effect of Dispersion of Particles Nanohybrid Reinforcing in the 6063 Aluminum Alloy
}

M.L. Camacho-Rios ${ }^{1}$, C.G. Garay-Reyes ${ }^{2}$, D. Lardizabal-Gutiérrez ${ }^{1}$, I. Estrada-Guel ${ }^{2}$, R. Perez-Bustamante ${ }^{3}$, G. Herrera-Perez ${ }^{4}$, A. Santos-Beltrán ${ }^{5}$, C.D. Gómez-Esparza ${ }^{6}$ and R. Martínez-Sánchez ${ }^{7}$

${ }^{1}$ Departamento de Metalurgia e IntegridadEstructural, Centro de InvestigaciónenMaterialesAvanzados (CIMAV), Avenida Miguel de Cervantes Saavedra 120, Complejo Industrial Chihuahua, 31136 Chihuahua, Chih., Mexico, United States, ${ }^{2}$ Centro de InvestigaciónenMaterialesAvanzados (CIMAV), Laboratorio Nacional de Nanotecnología, Miguel de Cervantes No. 120, CP 31136, Chihuahua, Chih., México., Chihuahua, Chihuahua, Mexico, ${ }^{3}$ CONACYT-Corporación Mexicana de InvestigaciónenMateriales S.A. de C.V. (COMIMSA), Coahuila, México. Eje 126 No. 225, Zona Industrial, 78395, San Luis Potosí, S.L.P. Mexico, United States, ${ }^{4}$ Centro de InvestigaciónenMaterialesAvanzados, Chihuahua, Chihuahua, Mexico, ${ }_{5}^{5}$ Departamento de Nanotecnología, Universidad Tecnológica de Chihuahua Sur, Km. 3.5 Carr Chihuahua Aldama, C.P., Aldama 31313, Chih., Mexico., United States, ${ }^{6}$ Universidad Autónoma de Ciudad Juárez, Ciudad Juarez, Chihuahua, Mexico, ${ }^{7}$ Centro de InvestigaciónenMaterialesAvanzados (CIMAV) Laboratorio Nacional de Nanotecnología, Miguel de Cervantes No. 120, CP 31136, Chihuahua, Chih., México., Chihuahua, Chihuahua, Mexico

Metal matrix composites (MMCs) are materials that present enhanced physical and mechanical properties compared to conventional metallic materials [1-2]. Among MMCs, the Al-based systems are promising engineering materials due to their low density and high specific strength [3]. Besides, there are significant research activities on reinforcements development of more than one component (Nanohybrid-NH) to improve the metallic matrix properties. Thus, this research aims to synthesize a novel 6063/CeO2/Gr composite to evaluate $\mathrm{NH}(\mathrm{CeO} 2 / \mathrm{Gr})$ influence on mechanical properties. The $\mathrm{CeO} 2 / \mathrm{Gr} \mathrm{NH}$ synthesis was performed following the same route reported by the authors in reference [4]. This study used a 6063 alloy (A6063) as the metallic matrix. The MMCs were produced incorporating powder nanoparticles of $\mathrm{CeO} / \mathrm{Gr}$ (ratio 8:1) $\mathrm{NH}$ at a final concentration of $5 \mathrm{wt}$. \%. The mechanical milling (MM) of the composites was performed at room temperature using a high-energy ball mill. The powder mass was $8.23 \mathrm{~g}$, and the ball-to-powder ratio was kept at 5:1. Argon and methanol were used as the milling atmosphere and process control agent, respectively. The milling time was set to $5 \mathrm{~h}$, based on previous results from Deaquino-Lara et al. [5] and Pérez-Bustamante et al. [6]. To carried out the mechanical characterization on solid samples, the milled powders were consolidated by uniaxial cold pressing at $1500 \mathrm{MPa}$ for $60 \mathrm{~s}$. Samples were compacted in cylindrical consolidation tooling of $6.7 \mathrm{~mm}$ of diameter and $12.3 \mathrm{~mm}$ of height and sintered under an argon atmosphere at $500{ }^{\circ} \mathrm{C}$ for $3 \mathrm{~h}$. Microstructural characterization was carried out through transmission electron microscopy (TEM) using a JEOL-JEM2200FS microscope. TEM specimens were prepared by focused ion beam (FIB) using a JEOL model JEM-9320 FIB. Mechanical characterization was conducted on the sintered composites using compression and microhardness Vickers (HV) testing, for which it was used an Instron machine model A3382 and a Leco LM300AT hardness tester, respectively. Fig. 1a shows an HRTEM image of CeO2/Gr NH used as reinforcing. Fig. $1 \mathrm{~b}$ is a magnified view of $\mathrm{CeO} 2 / \mathrm{Gr}$ NH into Fig. 1a (black square), which shows an interplanar

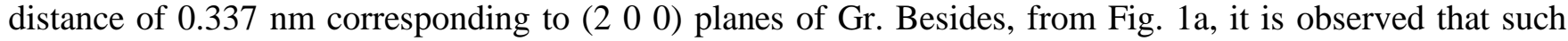
planes are parallel to $\left(\begin{array}{lll}1 & 1 & 1\end{array}\right)$ planes of $\mathrm{CeO} 2,(200) \mathrm{Gr} / /(111) \mathrm{CeO}$. The SAED pattern corresponding is shown in Fig. 1c, and finally, Fig. 1d presents STEM/EDS elemental mapping corresponding to the $\mathrm{CeO} 2 / \mathrm{Gr} \mathrm{NH}$, which confirms the homogeneous distribution of $\mathrm{Gr}$, and $\mathrm{CeO} 2$. Fig.2 shows the results of Yield stress (YS), Strain (e), and Vickers microhardness (HV) obtained from the compression and microhardness testing for sintered composite. Curves of YS ( $\mathbf{a})$ and HV $(\boldsymbol{\Delta})$ follow a similar behavior. The sample with lower YS and HV were sample A6063-non/milled. Comparing samples A6063- non/milled with A6063- milled observed the milling process's effect (reinforcement mechanisms of strain hardening and grain refinement) on YS and HV. 
However, the strengthening result is more critically observed in sample A6063- $\mathrm{CeO} 2 / \mathrm{Gr} \mathrm{NH}$ (reinforcement mechanisms of second phase dispersion and thermal mismatch). The Strain (•) shows an inverse response to YS and HV. The powder metallurgy processing of composites based in a 6063 alloy and CeO2/Gr nanohybrid produced a notable crystal refining and favored the reinforcing particles' homogeneous dispersion. The samples reinforced with nanohybrid present an additional increase in mechanical properties due to graphite transformation into A14C3. The primary strengthening mechanisms associated with the processing route are grain-size refining, the formation of the Al4C3 (strengthening by second phase dispersion), and the thermal mismatch.

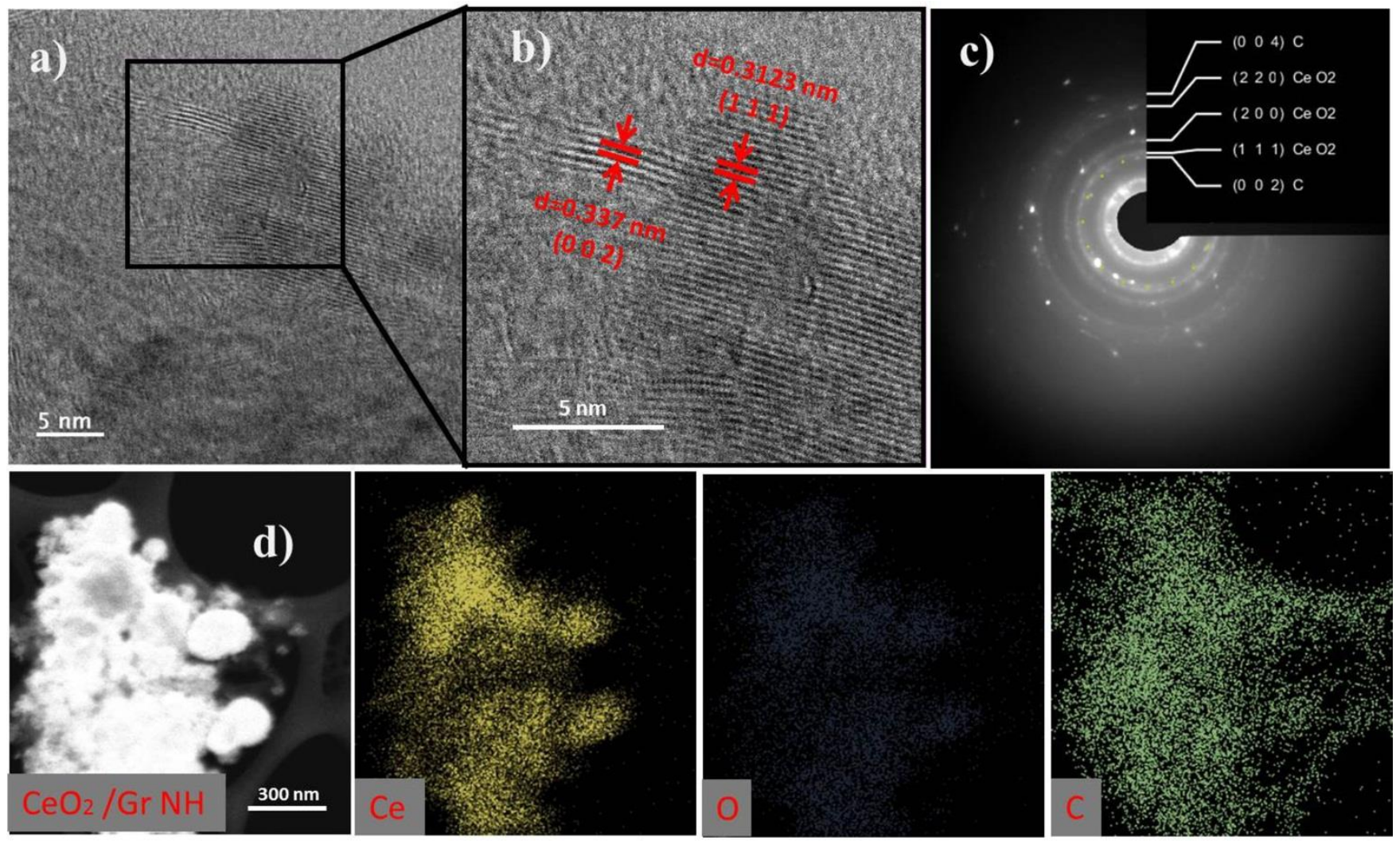

Figure 1. HRTEM micrographics (a,b), SAED pattern (c), and STEM/EDS elemental mapping (d) of CeO2/Gr NH. 


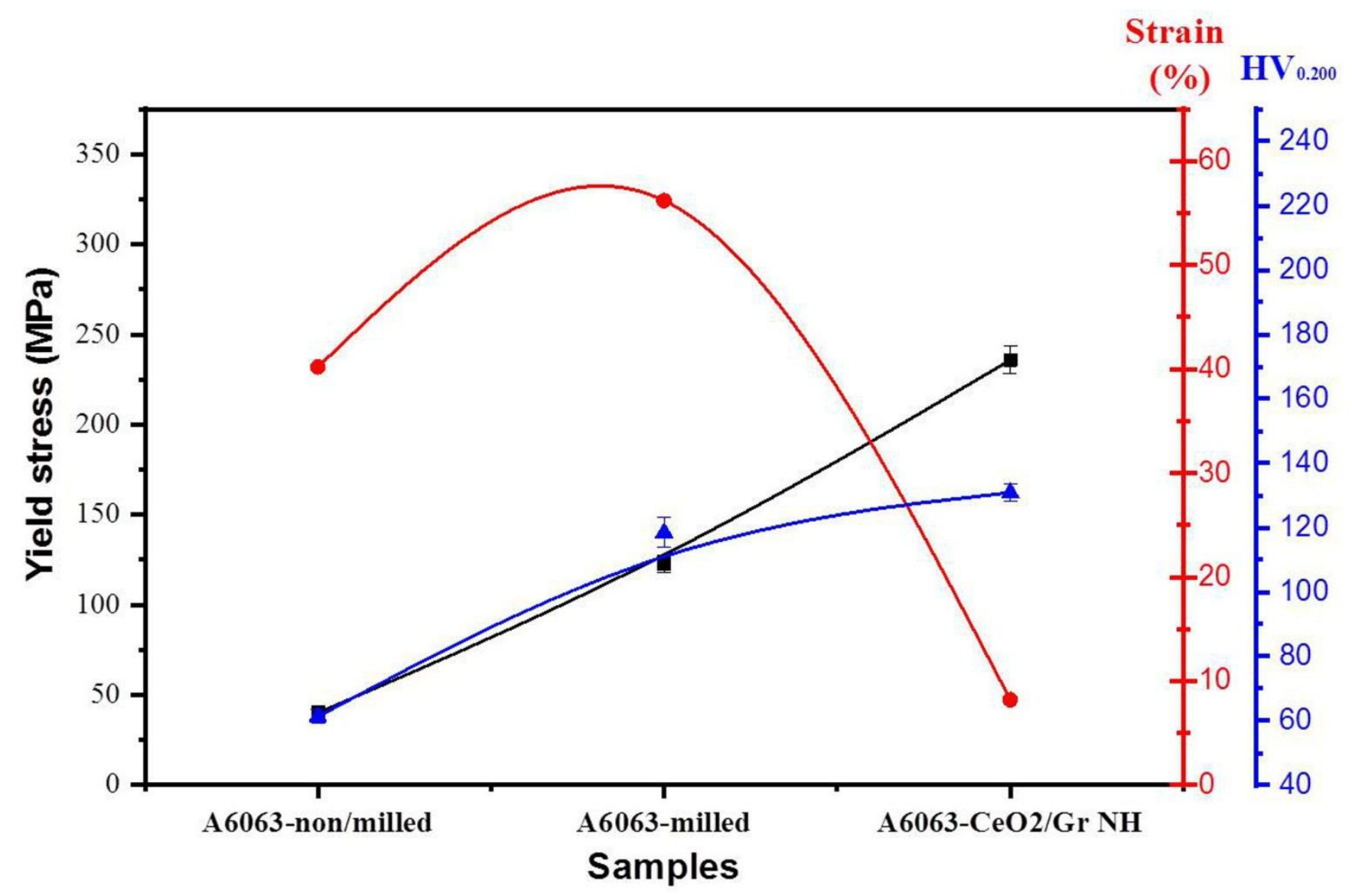

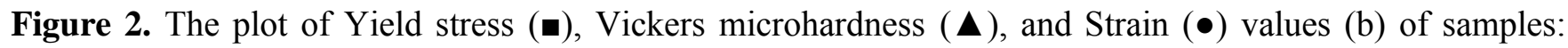
A6063- non/milled, A6063- milled, and A6063- CeO2/Gr NH.

\section{References}

[1] Wert JA. Microstructures of friction stir weld joints between an aluminium-base metal matrix composite and a monolithic aluminium alloy. Scripta Materialia. 2003;49:607-12.

[2] Ravi Kumar K, Kiran K, Sreebalaji VS. Microstructural characteristics and mechanical behaviour of aluminium matrix composites reinforced with titanium carbide. Journal of Alloys and Compounds. 2017;723:795-801.

[3] SinemAktaş EAD. A review on the effects of micro-nano particle size and volume fraction on microstructure and mechanical properties of metal matrix composites manufactured via mechanical alloying. International Advanced Researches and Engineering Journal 2018;02:068-74.

[4] Camacho-Ríos ML, Cristóbal-García JD, Lardizabal-Gutiérrez D, Estrada-Guel I, Herrera-Pérez G, PiñónEspitia M, Martínez-Sánchez R. The influence of chelating agents on cerium oxide decorated on graphite synthesized by the hydrothermal route. Ceramics International. 2020;46:18791-18799.

[5] Deaquino-Lara R, Estrada-Guel I, Hinojosa-Ruiz G, Flores-Campos R, Herrera-Ramírez JM, MartínezSánchez R. Synthesis of aluminum alloy 7075-graphite composites by milling processes and hot extrusion. Journal of Alloys and Compounds. 2011;509:S284-S9. 
[6] Pérez-Bustamante R, Bolaños-Morales D, Bonilla-Martínez J, Estrada-Guel I, Martínez-Sánchez R. Microstructural and hardness behavior of graphene-nanoplatelets/aluminum composites synthesized by mechanical alloying. Journal of Alloys and Compounds. 2014;615:S578-S82. 